Macdonald, I. (1967a). Wld Rev. Nutr. Diet. 8, 143.

Macdonald, I. (1967b). Am. F. clin. Nutr. 20, 345 .

Macdonald, I. (I970). Br. F. Nutr. 24, 537.

Macdonald, I. (I971). In Balanced Nutrition and Therapy p. 100 [K. Lang, W. Fekl and G. Berg, editors]. Stuttgart: Verlag.

Nikkila, E. A. \& Kekki, M. (1971). Scand. \%. clin. Lab. Invest. 27, 97.

Nikkila, E. A. \& Taskinen, M. R. (1970). In Atherosclerosis p. 220 [R. J. Jones, editor]. Heidelberg: Springer-Verlag Berlin.

Perry, W. F. \& Corbett, B. N. (1964). Can. F. Physiol. Pharmac. 42, 353.

Roberts, A. M. (197r). Proc. Nutr. Soc. 30, 7 IA.

Togel, O., Brezina, E. \& Durig, A. (19 13). Biochem. Z. I, 296.

Van Heyningen, R. (1959). Nature, Lond. 183, Suppl. no. 4, r94.

Wolf, H. P. \& Leuthardt, F. (1953). Helv. chim. Acta 36, 1463.

Yudkin, J. (1964). Lancet $\mathrm{ii}_{3} 4$.

\title{
The role of insulin in the regulation of glucose metabolism
}

\author{
By C. N. HaLes, Department of Chemical Pathology, Welsh National School \\ of Medicine, Heath Park, Cardiff
}

One of the most important routes through which the dietary availability of carbohydrate regulates metabolism is through the secretion and action of insulin. The other hormonal mechanisms which mediate metabolic adaptation to carbohydrate deficiency are much less clearly understood. This paper is limited, therefore, to the mechanism of glucose-stimulated insulin release and of insulin-regulated glucose metabolism and storage. Insulin secretion has recently been reviewed by Mayhew, Wright \& Ashmore (1969) and Randle \& Hales (1971).

\section{Insulin release}

A diagramatic representation of the extra- $\beta$-cell factors which may be involved in the whole process by which dietary carbohydrate regulates insulin secretion is shown in Fig. I.

Nervous system. The effects of the autonomic nervous system and its neurotransmitters on insulin release are consistent with the known role of the system in digestion and absorption. Vagal stimulation in the baboon (Daniel \& Henderson, I968) leads to an increased release of insulin into the portal vein. Conversely, adrenaline and noradrenaline are powerful inhibitors of insulin secretion. The possibility exists, therefore, that the sight, smell and taste of food are factors capable of increasing insulin release through activation of the parasympathetic and inhibition of the sympathetic nervous systems. It has been shown that the pancreatic islets of various species are richly innervated (Lever \& Findlay, 1971).

Gut factors. The route of administration of glucose has been shown to affect the size of the insulin response. When the same degree of hyperglycaemia is produced by the intravenous or intraduodenal infusion of glucose, the resulting insulinaemia is greater during the latter infusion. This has given rise to the suggestion that intraduodenal glucose or, indeed, amino acids may stimulate the release of a gut hormone 


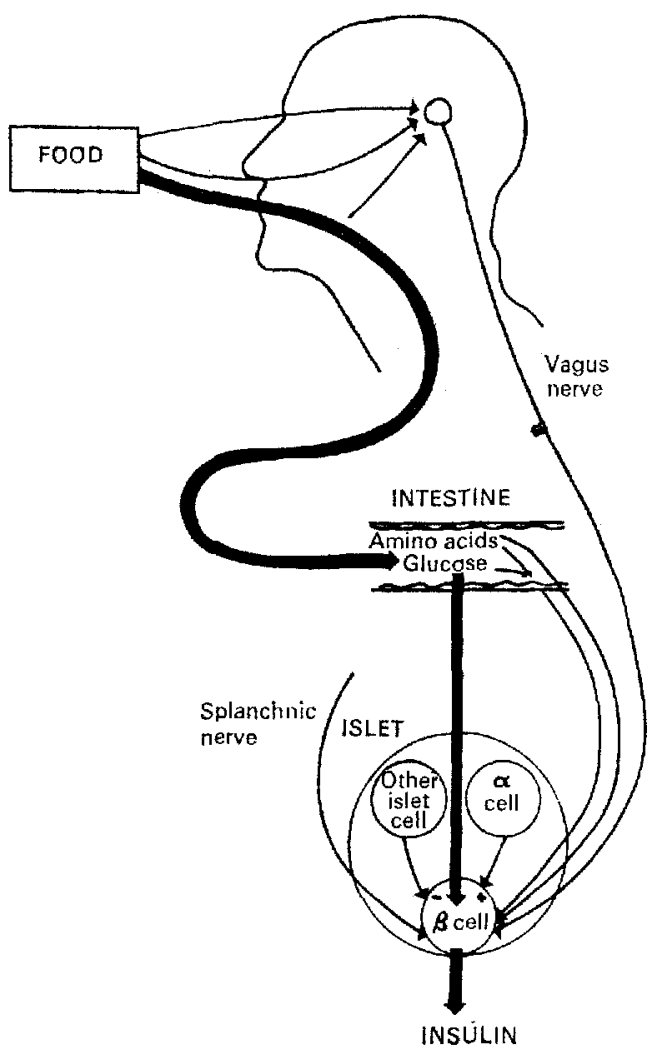

Fig. I. Some of the possible extra $\beta$-cell factors affecting insulin secretion.

which then stimulates insulin release. The identity of this hormone or hormones is not known. Among the substances which have been shown to stimulate insulin release are glucagon, gut glucagon-like substances, secretin and pancreozymin. However, attempts to induce endogenous secretin and pancreozymin to stimulate insulin secretion in vivo in man by the administration of intraduodenal acid have not proved successful (Boyns, Jarrett \& Keen, r966; Mahler \& Weisberg, r968).

Islet hormones. The fact that glucagon is capable of potentiating glucose-stimulated insulin secretion raised the possibility that glucagon released by the $\alpha$-cells in the islet might act similarly. Against this possibility is the fact that $\alpha$-cell glucagon release is suppressed by increasing glucose concentrations and the observations that the release of insulin by isolated islets in response to glucose is not inhibited by the presence of anti-glucagon serum (Malaisse \& Malaisse-Lagae, r 968). These findings do not eliminate the possibility that other stimuli of insulin release such as amino acids could act via an effect to produce high local concentrations of glucagon in the islet.

Some evidence has been obtained which suggests that other cells in the islet may release a factor which inhibits insulin secretion and that this may be a gastrin-like substance (Hellman \& Lernmark, r970). 


\section{Mechanism of glucose stimulation}

Studies of glucose-stimulated release by the perfused rat pancreas have shown a biphasic pattern of release (Curry, Bennett \& Grodsky, rg68). There is an early response lasting about $5 \mathrm{~min}$ and a sustained late rise continuing for over an hour. Most studies of the mechanism of the glucose effect have been concerned with secretion over periods considerably longer than $5 \mathrm{~min}$ and, therefore, relate more to the mechanism of the sustained response. The relationship between glucose concentration and insulin release has been carefully characterized in the hope that it would yield information concerning the nature of the glucoreceptor mechanism. Clearly, the latter should be capable of responding to effects of changes in glucose concentration in the same range as those which stimulate insulin release. To this end the glucose concentration giving half maximum stimulation of release has been found to be in the region of $10-20 \mathrm{mmol} / \mathrm{l}$, with a threshold at about $5 \mathrm{mmol} / \mathrm{l}$. While the argument relating to the range of receptor sensitivity is sound, that utilizing the maximum rate of release is not. Maximum rates of insulin release may well be imposed by the release mechanism itself and not relate to saturation of the glucoreceptor.

The signal by which glucose initiates the events leading to insulin release may be glucose itself or some metabolite produced as a result of glucose metabolism. Experiments to differentiate between these two possibilities have utilized inhibitors, studies of the effects of other sugars and measurement of changes in the concentration of intermediates of metabolism in isolated islets.

Phloridzin, an inhibitor of glucose transport, does not inhibit glucose stimulation of insulin release. This suggests that a phloridzin-sensitive glucose transport system is not an essential component of the glucose stimulation mechanism. Islet intracellular glucose concentrations rapidly equilibrate with blood glucose concentrations suggesting that transport is not a rate-limiting step in glucose utilization by the tissue. This does not of course exclude the possibility that a rapid, phloridzininsensitive transport system is the glucoreceptor mechanism. However, evidence that intracellular glucose metabolism is essential for the production of a signal mediating stimulation of insulin release has come from the inhibiting effect on the process of the seven-carbon sugar, mannoheptulose. This sugar is known to inhibit glucose phosphorylation by the liver hexokinase $(E C$ 2.7.r.I) and is thought to act similarly in the $\beta$-cell. Consistent with the theory that glucose metabolism is essential for stimulation of insulin release are the observations that mannose has a similar effect but that the less readily metabolized sugars such as fructose, galactose, 3-0methyl glucose and 2-deoxyglucose have little or no effect. The latter sugar has been used as an inhibitor (in the phosphorylated form) of glucosephosphate isomerase (EC 5.3.r.9) but general agreement as to its ability to inhibit glucosestimulated insulin release has not been reached.

Glucose metabolism to $\mathrm{CO}_{2}$ by isolated islets shows kinetics similar to those of glucose stimulation of insulin release, supporting the view that the rate-limiting step in glucose metabolism is also that serving as the glucoreceptor. That this 
step could be glucose phosphorylation is suggested by the similar kinetics which relate mouse islet glucose-6-phosphate concentrations to extracellular glucose concentrations. A glucose phosphorylating enzyme with a high $K m$ for glucose has been detected in homogenates of mouse islets. The possibility that further metabolism of glucose via the pentosephosphate pathway may be necessary for the generation of the signal linking insulin release to glucose metabolism has been suggested by the stimulatory effects of pentoses and pentitols and by the changes in islet 6-phosphogluconate concentrations.

Two other important aspects of the glucoreceptor mechanism are its apparent ability to undergo adaptation to the carbohydrate intake and its link to protein synthesis. Carbohydrate deprivation leads to a decrease in the glucose stimulation of insulin secretion. This loss occurs at a time when the islet insulin content has not fallen significantly. Conversly, obese subjects (Karam, Grodsky \& Forsham, 1963) and rats with experimental obesity (Hales \& Kennedy, 1964) show an increased insulin response to glucose. It was suggested that the latter change could be caused by the increased carbohydrate intake which leads to adaptive changes in the metabolism of the $\beta$-cell.

Further support for a carbohydrate-induced adaptive change in the sensitivity of the insulin release mechanism to glucose has come from recent work by Grey, Goldring \& Kipnis (1970). The depressed insulin response to glucose in vivo of rats fasted for $48 \mathrm{~h}$ was back to $40 \%$ of the fed response $7 \mathrm{~h}$ after refeeding a normal diet and was completely restored after $24 \mathrm{~h}$. The ability of refeeding to increase the insulin response was blocked by actinomycin $\mathrm{D}$ and was due to the carbohydrate content of the diet. These changes were independent of changes in the insulin content of the pancreas.

Glucose nevertheless does have an effect of increasing insulin synthesis (Taylor, I964). The kinetics of this effect resemble those of glucose-stimulated insulin release. The effect is inhibited by mannoheptulose and involves an increase in the synthesis of proinsulin (Morris \& Korner, 1970). It is not known whether the same signal mediates the glucose effect on insulin release and synthesis. Since the drug tolbutamide, which seems to utilize a similar final mechanism of insulin release (Milner $\&$ Hales, 1969), does not stimulate insulin synthesis, linkage of the glucose effect with glucose metabolism would appear likely.

The final events linking glucose stimulation with insulin release appear to have many features in common with other stimuli of insulin release. There is a requirement for extracellular $\mathrm{Ca}^{++}$and $\mathrm{Na}^{+}$with inhibition by manoeuvres designed to inhibit ATP production. Glucose induces a characteristic sequence of miniature action potentials which appear to represent the influx of extracellular $\mathrm{Ca}^{++}$(Dean \& Matthews, I970). It is possible that the influx of $\mathrm{Ca}^{++}$takes place in exchange for intracellular $\mathrm{Na}^{+}$since manipulations aimed at raising $\beta$-cell $\mathrm{Na}^{+}$concentration stimulate insulin release (Hales \& Milner, r968).

Procedures which are likely to raise $\beta$-cell $3^{\prime} 5^{\prime}$ cyclic AMP concentration potentiate stimulation of insulin release. This effect is unlikely to be solely due to effects of $3^{\prime} 5^{\prime}$ cyclic AMP on glucose metabolism since the same procedures potentiate 


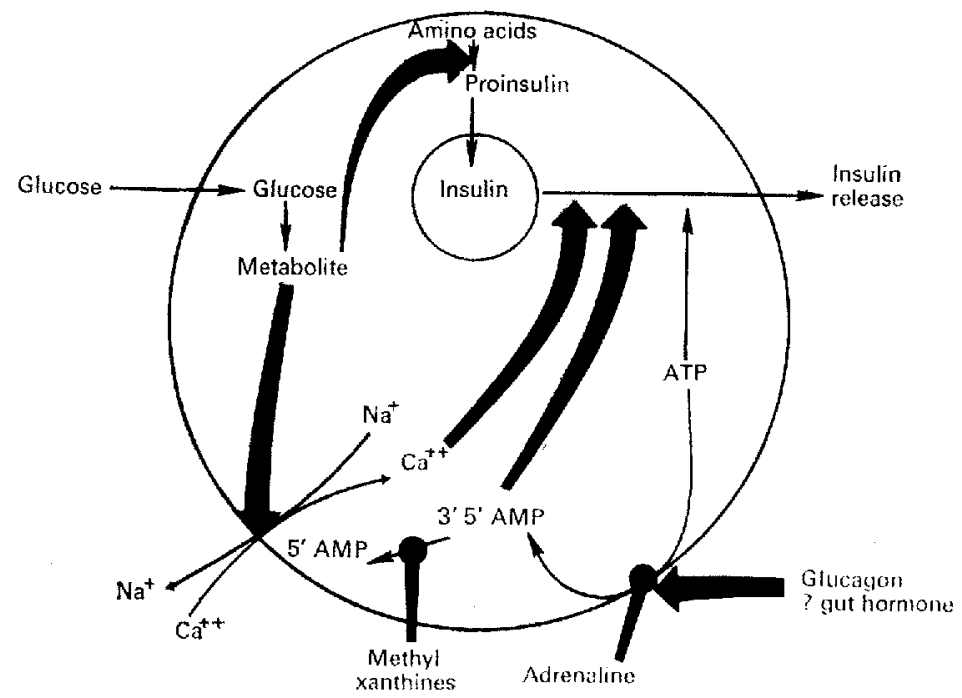

Fig. 2. Hypothetical scheme of the mechanism of glucose-stimulated insulin secretion. inhibition.

amino acid and ionic stimuli of release. A possible scheme for the mechanism of glucose-stimulated insulin secretion is shown in Fig. 2.

A hypothesis (Rasmussen, 1970) which attempts to link these characteristics of the release mechanism considers release to be mediated via a system of microtubules (Lacy, 1970). Insulin secretion is indeed inhibited by colchicine which causes the disappearance of microtubules in other cells. It is suggested that contraction of the microtubules requires ATP and is induced by $\mathrm{Ca}^{++}$with potentiation by $3^{\prime} 5^{\prime}$ cyclic AMP.

\section{Insulin action}

The role of insulin in the regulation of glucose metabolism is best understood in the rat. Extreme caution must be exercised in extrapolating results of insulin effects from one species to another. Such evidence as there is suggests that the role of insulin is likely to differ between species. Studies of the comparative sensitivity to insulin of adipose tissue show that the tissue can be extremely sensitive to the antilipolytic effect of insulin ( $0.1 \mu \mathrm{U} / \mathrm{ml}$ in rat and man) or totally insensitive to this action (no effect of $100 \mathrm{mU} / \mathrm{ml}$ in the chicken).

In the rat, insulin released in response to glucose stimulation acts to promote glucose metabolism and storage as glycogen and triglyceride. The most sensitive tissue is undoubtedly adipose tissue in which a number of sites of insulin action on carbohydrate metabolism have been identified. It is considered in this context that effects of insulin on triglyceride synthesis and hydrolysis are most reasonably considered nutritionally as sites through which effects of insulin on carbohydrate storage and metabolism are mediated. A recent review of the action of insulin on adipose tissue is that edited by Jeanrenaud \& Hepp (1970). 
Glucose transport. Insulin stimulates glucose uptake by adipose tissue. This effect is considered to be due to a stimulation of transport since it leads to accumulation of glucose within the cell; it is also seen on the inward and outward transport of non-metabolizable sugars and can be shown in subcellular particles which metabolize glucose poorly or not at all. A similar effect of insulin can be demonstrated in muscle. Glucose uptake by this tissue is also stimulated by anoxia and interference with oxidative phosphorylation. Several years ago it was suggested that the regulation of glucose transport might occur via phosphorylation and dephosphorylation. Insulin might act by causing a dephosphorylation of the (inhibited) glucose carrier. No further progress has been made in elucidating the mechanism of the insulin effect. Pretreatment of adipose tissue cells with insulin leads to an increased glucose uptake by microsomal particles derived from the cells but the particles themselves are not directly sensitive to insulin (Martin \& Carter, I970).

A number of other sites of action of insulin on glucose metabolism and storage in adipose tissue have been identified. Insulin leads to an activation of UDP glucose-glycogen glucosyltransferase (EC 2.4.I.II) and pyruvate dehydrogenase (EC 1.2.2.2) (Denton, Coore, Martin \& Randle, 1971) and to an inhibition of adrenaline-stimulated lipolysis. It is possible that all of these effects are mediated by dephosphorylation of a phosphorylated enzyme. This effect in turn could be mediated via an effect of insulin to lower adipose tissue $3^{\prime} 5^{\prime}$ cyclic AMP concentrations. This is not the complete answer to the mechanism of the insulin effect, however, as the effects of insulin on muscle glycogen synthetase appear to be independent of changes in the $3^{\prime} 5^{\prime}$ cyclic AMP content of that tissue and changes in $3^{\prime} 5^{\prime}$ AMP concentration do not seem to account for insulin effects on glucose transport. It is not as yet clearly established whether insulin lowers adipose tissue $3^{\prime} 5^{\prime}$ cyclic AMP concentrations by inhibition of adenylate cyclase or by activation of phosphodiesterase or both.

\section{REFERENCES}

Boyns, D. R., Jarrett, R. J. \& Keen, H. (1966). Lancet i, 409.

Curry, D. L., Bennett, L. L. \& Grodsky, G. M. (1968). Endocrinology 83, 572.

Daniel, P. M. \& Henderson, J. R. (1968). F. Physiol., Lond. 214, 74 .

Dean, P. M. \& Matthews, E. K. (1970). F. Physiol., Lond. 210, 265.

Denton, R. M., Coore, H. G., Martin, B. R. \& Randle, P. J. (I971). Nature New Biol. $231,115$.

Grey, N. J., Goldring, S. \& Kipnis, D. M. (1970). In Pathogenesis of Diabetes Mellitus, Nobel Symposium No. I3, p. I55 [E. Cerasi and R. Luft, editors]. New York: John Wiley and Sons Inc.

Hales, C. N. \& Kennedy, G. C. (1964). Biochem. F. 90, 620.

Hales, C. N. \& Milner, R. D. G. (1968). F. Physiol., Lond. 194, 725.

Hellman, B. \& Lernmark, A. (I970). In Structure and Metabolism of the Pancreatic Islets p. 453 [S. Falkner, B. Hellman and I. B. Taljedal, editors]. Oxford: Pergamon Press.

Jeanrenaud, B. \& Hepp, D. (editors). (1970). Adipose Tissue Regulation and Metabolic Function, suppl. 2, Hormone and Metabolic Research. Stuttgart: Georg Thieme Verlag.

Karam, J. H., Grodsky, G. M. \& Forsham, P. H. (1963). Diabetes 12, I97.

Lacy, P. E. (1970). In Pathogenesis of Diabetes Mellitus, Nobel Symposium No. 13, p. rog [E. Cerasi and R. Luft, editors]. New York: John Wiley and Sons Inc.

Lever, J. D. \& Findlay, J. A. (1971). Endocr. Mem. no. 19, p. 437. London: Cambridge University Press.

Mahler, R. J. \& Weisberg, H. (I968). Lancet i, 448.

Malaisse, W. \& Malaisse-Lagae, F. (1968). Acta Diabet., Latina 5, suppl. no. 1, p. 64. 
Martin, D. B. \& Carter, J. R. Jr (1970). Science, N.Y. r67, 873.

Mayhew, D. A., Wright, P. H. \& Ashmore, J. (1969). Pharmac. Rev. 21, 183.

Milner, R. D. G. \& Hales, C. N. (1969). Biochem. F. 113, 473.

Morris, G. E. \& Korner, A. (1970). Biochem. biophys. Acta 208, 404.

Randle, P. J. \& Hales, C. N. (197I). In Handbook of Physiology, Sect. Endocrinology [E. B. Astwood and R. O. Greep, editors]. Washington, D.C.: American Physiological Society. (In the Press.)

Rasmussen, H. (1970). Science, N.Y. 170, 404.

Taylor, K. W. (1964). Ciba Fdn Colloq. Endocr. $15,89$. 